\title{
Environmental Analysis of the COVID-19 pandemic in Saudi Arabia: A Study in Medical Geography
}

\author{
Mohamed Nour Eldin Elsabawy ${ }^{1}$ and Sahar Mohamed Elzeeny ${ }^{2,3 *}$ \\ ${ }^{1}$ Professor of Medical Geography, Minia University, Egypt \\ ${ }^{2}$ Ph.D. in Medical Geography, Tanta University, Egypt \\ ${ }^{3}$ Formerly Assistant Professor, Qassim University, Saudi Arabia
}

Submission: September 20, 2021; Published: November 08, 2021

*Corresponding author: Sahar Mohamed Elzeeny, Ph.D. in Medical Geography, Tanta University, Egypt \& Formerly Assistant Professor, faculty of Science and Arts, Qassim University, Saudi Arabia

\begin{abstract}
This study is one of the micro studies that is concerned with analyzing the geographical environment of a global epidemic within a specific geographical scope, in which the rates of infection with the Covid19 pandemic in the Saudi Arabia were compared with other local, regional and global regions to determine the extent of its spread and speed of arrival, and the distribution of morbidity, recovery and fatality rates was also linked. The study relied on several approaches, including the inductive approach, disease Ecology and Disease Diffusion approach, as well as statistical and quantitative analysis using the stepwise regression method, and the cartographic representation method, and the study reached a set of results, the most important of which are The success of the Saudi Arabia at the international and regional levels in dealing with the epidemic, as it was able to reduce the growth of infection cases, and fell from the forefront of the Arab countries in the number of infected cases to the third, and from the thirteenth to the thirty-fifth globally, and began to decline further after the application of vaccines For all those within its borders, it was also able to maintain average infection rates of 1041.9 for every 100 thousand people at the end of 2020, which is slightly less than the global average of about 1069 per 100 thousand people, and low death rates did not exceed $1.7 \%$, while the global rate was $2.2 \%$, and therefore the growth of recovery rates increased to reach $97.5 \%$ in light of Continuous prevention and examination procedures and treatment services.
\end{abstract}

At the level of the Saudi's regions, regional discrepancies were found clearly, as morbidity and recovery rates increased in the east and southwest of the state and extended to the West, where the Eastern Province, Madinah and Asir recorded the highest morbidity rates, and recovery rates exceeded $98 \%$, while morbidity rates decreased in the north and center, especially in the Al-Jawf region, Tabuk and the northern borders, and the death rates increased in the northern part, where the Al-Jawf region and the northern borders recorded rates ranging from 3.5 $-4.2 \%$. For reasons related to movement, density, and degree of crowding.

When analyzing the environmental impact of some health and social factors affecting the rates of morbidity and fatality in the pandemic in the regions of the Saudi Arabia using the method of stepwise regression analysis, the association of infection with some infectious diseases such as amoebic dysentery as an indicator of disease infection came in the forefront of the independent variables and the relationship was significant, then followed by a variable availability of the health service represented in the availability of isolation beds, and the availability of chest physicians came at the forefront of the independent variables included in the regression analysis of the fatality rate variable, followed by the variable population density, Then the nursing / physician.

Keywords: Covid19; Pandemic; Morbidity rate; Fatality rate; Stepwise regression; Saudi Arabia

\section{Introduction}

Despite the delay in the appearance of the first case of the Covid19 epidemic in the Saudi Arabia for the second of March 2020, that is, two months after the announcement of its appearance in the world, the cases continued to increase until the state became, before the end of March, the first Arab country in cases of infection with the virus, The increase continued until the cases of infection at the end of August 2020 exceeded the 300,000 cases, and about 3900 deaths, and ranked 13th globally, but due to the changing nature of the disease and the instability of its conditions, its order changed at the end of September to occupy the second place after Iraq in the number of infects and the order 17 Globally, despite the increase in the number of infects until the 
end of December 2020 reached about 362.7 thousand cases, and about 6,223 deaths, the Saudi Arabia has fallen to the third Arab rank after Iraq and Morocco, and 35 globally.

It was noted when following up on the announcement of cases of infection and death from the epidemic in the Saudi Arabia that the most affected regions were the Eastern Province, Makkah, Riyadh, especially Riyadh, Jeddah, Makkah, Dammam cities, which called for the need to study the reasons for this disparity in the geographical distribution at the level of Regions, mapping rates of morbidity, recovery and fatality and analyzing them geographically, as it becomes clear when studying the rate that the most affected regions are, which may lead to predicting the places most at risk of spreading infection in the future, when taking into account some social, health, environmental and behavioral factors in the region.

The Saudi Ministry of Health had taken proactive measures to circulate access to the vaccine, whose beneficiaries reached more than seven million citizens and residents until April 20, 2021, through 587 vaccination sites in all regions of the Saudi Kingdom, and this led to a decrease in the number of deaths to 9 cases only on Saturday. Corresponding to April 17, 2021, the total number of people recovered was 387,795 .

\section{Reasons of Study}

One of the main reasons for choosing this topic was that the number of people infected at the beginning of the disease was the highest in the Saudi Arabia at the level of the Arab world, and the fifth in terms of morbidity rates, and that as a religious destination for arrivals from all countries of the world to perform the rituals of Hajj and Umrah On the one hand, this is in addition to being an access point for expatriate workers from various countries of the world and Southeast Asia in particular, with their diversity in social, behavioral and cultural habits, which can have an impact on varying rates of morbidity, recovery and fatality.

However, due to the changing nature of the disease and the instability of its conditions, the ranking of Arab and non-Arab countries in the number of infected people as well as in morbidity rates changed, so that Iraq surpassed the countries of the entire Arab world in the number of infected people with about 595.3 thousand cases by the end of December 2020, followed by Morocco, then Saudi Arabia with about 362.7 thousand cases [1]. Bahrain advanced in morbidity rates of 5431.7 per 100,000 people, while the Saudi Arabia lagged to thirteenth rank with a rate of 1041.9 , which is lower than the global average of about 1069 per 100,000 people.

\section{Research Aim}

This research aims to identify the cases and morbidity rates with the Covid19 epidemic in the Saudi Arabia compared to the countries of the world on the one hand, and the regions of the
Saudi Arabia on the other hand, within the limits of the available statistical data, and to analyze it using advanced statistical analysis methods in the style of stepwise regression, and ANOVA, and the study excludes variables that have no statistical significance. The research aims to study the geographical conditions affecting these rates, then the study concludes with a set of proposals and recommendations that help reduce the risk of the epidemic in the future.

\section{Research questions (hypothesis)}

The research answers a number of questions:

1) There are differences between Saudi Arabia and other countries of the world in the Morbidity, recover, and fatality rates .

2) There are differences between Saudi Arabia and the Arab countries in the morbidity, recovery and fatality rates.

3) There are no differences between the regions of Saudi Arabia in the morbidity, recovery and fatality rates.

4) Climatic conditions have a role in the high rates of morbidity and fatality rates in Saudi Arabia.

5) Conditions of the human environment in Saudi Arabia, such as population density, degree of crowding, urbanization, health status, and the level of health care, explain the differences in morbidity and fatality rates.

\section{Methods and Materials}

The approach of this research is including the inductive approach, by studying the development of infection cases in the state and comparing them with those in the Arab countries and the world, and the analytical approach, associative relatives. It also relied on some approaches in medical geography, such as the Disease Diffusion approach when studying spatial variations in morbidity rates in the regions of the Saudi Arabia and its geographical analysis, as well as the behavioral trend and the cartographic representation, statistical analysis based on SPSS program, Excel, and Arc GIS program.

\section{A Temporal Analysis of the Corona Epidemic in Saudi Arabia \\ Cases of infection compared to the countries of the Arab world}

The number of cases infected with the Covid-19 pandemic in Saudi Arabia until the end of December 2020 amounted to about 362.7 thousand cases, about $11.1 \%$ of the total cases in the Arab world (3.268 million cases), ranking third after the state of Iraq and Morocco, after it was The first until the end of August 2020, and $0.4 \%$ of the total cases in the world to occupy the thirty-fifth rank globally [2], and when following up the development of pandemic cases in Saudi Arabia and comparing it with its counterparts from Arab countries Table 1, on the logarithmic curve Figure 1. 


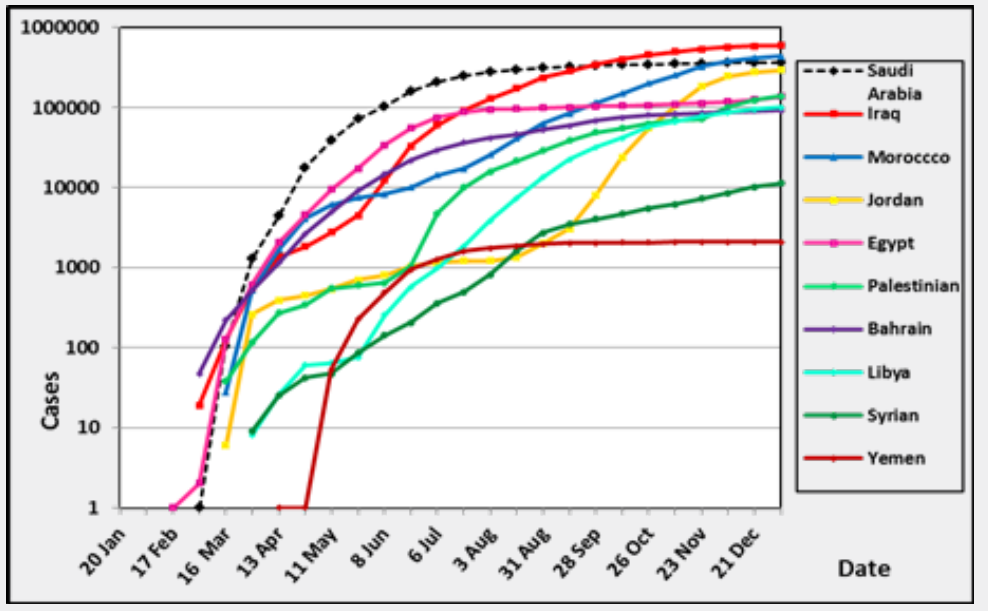

Figure 1: Comparison of Covid19 logarithm curve between Saudi Arabia and Arab world during the period from 20 January to 31 December 2020.

Source: researcher design depending on: W.H. O., 2020. Coronavirus disease 2019 (COVID-19) Situation Report, I-196. https:// corona-v.com (17 August-31 December2020).

Table 1: Comparison of Covid19 cases between Saudi Arabia and Some Arab countries during the period from 20 January to 31 December 2020.

\begin{tabular}{|c|c|c|c|c|c|c|c|c|c|c|}
\hline Date & Saudi Arabia & Iraq & Morocco & Jordan & Egypt & Palestinian & Bahrain & Libya & Syrian & Yamen \\
\hline \multicolumn{11}{|l|}{20 Jan } \\
\hline \multicolumn{11}{|l|}{3 Fab } \\
\hline $17 \mathrm{Fab}$ & & & & & 1 & & & & & \\
\hline 2 Mar & 1 & 19 & 0 & 0 & 2 & 0 & 47 & 0 & 0 & 0 \\
\hline 16 Mar & 103 & 124 & 28 & 6 & 126 & 38 & 221 & 0 & 0 & 0 \\
\hline 30 Mar & 1299 & 547 & 516 & 259 & 609 & 115 & 515 & 8 & 9 & 0 \\
\hline $13 \mathrm{Apr}$ & 4462 & 1352 & 1661 & 389 & 2065 & 271 & 1136 & 26 & 25 & 1 \\
\hline $27 \mathrm{Apr}$ & 17522 & 1820 & 4065 & 447 & 4534 & 342 & 2647 & 61 & 42 & 1 \\
\hline 11 May & 39048 & 2767 & 6063 & 540 & 9400 & 547 & 4941 & 64 & 47 & 53 \\
\hline 25 May & 72560 & 4469 & 7433 & 708 & 17265 & 602 & 9138 & 75 & 86 & 226 \\
\hline 8 Jun & 101914 & 12366 & 8224 & 808 & 34079 & 643 & 14763 & 256 & 141 & 488 \\
\hline 22 Jun & 157612 & 32676 & 9977 & 1033 & 55233 & 1028 & 21764 & 571 & 204 & 945 \\
\hline $6 \mathrm{Jul}$ & 209509 & 60479 & 14215 & 1164 & 75253 & 4722 & 29367 & 989 & 358 & 1269 \\
\hline $20 \mathrm{Jul}$ & 250920 & 92530 & 17236 & 1218 & 87775 & 10052 & 36422 & 1866 & 496 & 1610 \\
\hline 3 Aug & 278835 & 129151 & 25537 & 1213 & 94483 & 15780 & 41536 & 3837 & 809 & 1738 \\
\hline 17 Aug & 297315 & 172583 & 41017 & 1339 & 96336 & 21554 & 46430 & 7327 & 1593 & 1862 \\
\hline 31 Aug & 315772 & 234934 & 62590 & 1993 & 98939 & 28927 & 52750 & 13450 & 2700 & 1960 \\
\hline 14 Sep & 325050 & 286778 & 84435 & 3062 & 100856 & 38516 & 59586 & 22548 & 3506 & 2013 \\
\hline 28 Sep & 332790 & 345969 & 115241 & 8061 & 102736 & 48572 & 68775 & 31828 & 4038 & 2034 \\
\hline 12 Oct & 338944 & 400124 & 149841 & 23998 & 104387 & 55134 & 75287 & 41686 & 4673 & 2055 \\
\hline 26 0ct & 345232 & 455398 & 199745 & 55055 & 106707 & 62588 & 80533 & 57223 & 5461 & 2064 \\
\hline 9 Nov & 350229 & 496019 & 252185 & 104802 & 108962 & 69612 & 83264 & 67039 & 6147 & 2070 \\
\hline $23 \mathrm{Nov}$ & 355258 & 535321 & 324941 & 183429 & 113027 & 71644 & 85705 & 77823 & 7225 & 2069 \\
\hline $7 \mathrm{Dec}$ & 358922 & 566015 & 381188 & 244069 & 118847 & 99758 & 88111 & 87097 & 8490 & 2078 \\
\hline $21 \mathrm{Dec}$ & 361178 & 585345 & 417125 & 277448 & 125555 & 123945 & 90282 & 95200 & 10195 & 2087 \\
\hline $31 \mathrm{Dec}$ & 362741 & 595291 & 437332 & 294494 & 136644 & 138004 & 92425 & 100277 & 11344 & 2097 \\
\hline
\end{tabular}

Source: researcher design depending on: W.H.O., 2020. Coronavirus disease 2019 (COVID-19) Situation Report, I-196. https://corona-V.com (17 August-31 December 2020). 
The infection curve in the Saudi Arabia began to rise rapidly, reaching its peak, exceeding 100,000 infects at the beginning of June, i.e., during the first three months of the announcement of the first case of infection, and this is due to the fact that the Saudi Arabia represents an arrival and transit station during the Hajj and Umrah seasons through 27 airports. There are 13 international airports, and 3 international sea ports are Deba, Jeddah and Yanbu, as well as its location, which is adjacent to seven Arab countries, with which it has fourteen land border ports [3], and three ports are with Jordan, an outlet with Iraq, two with Kuwait, an outlet with Bahrain, another with Qatar, an outlet with the Emirates, another with Oman, and 4 outlets with Yemen, in which the population moves back and forth, and all of this helped in the rapid spread of the disease among the population of the Saudi Arabia, especially at the beginning of its appearance. And before it took the epidemiological form and declared it as a pandemic, then the curve began to slow growth and relative stability, and then the rate of growth of infections declined at the end of August 2020 , which was related to the application of preventive measures and social distancing that the state applied to stop the spread of the epidemic, and a strong commitment to One of the studies conducted early to identify the level of health environmental awareness in the practices of members of the Saudi society to deal with the pandemic showed that $37.7 \%$ of the total sample of the study follow up on developments about the Corona virus daily, and that the levels of awareness of health environmental security measures appropriate to the pandemic were high and confirmed, The study showed that females are more committed to health security practices [4].

The closure of the Saudi Arabia airports and the suspension of Umrah flights, as the number of Umrah pilgrims decreased in 2020 by $69.6 \%$ compared to 2019 as a result of the closure process that took place after the announcement of Covid-19 cases in the Kingdom in March 2020 [5], and limiting the pilgrimage in 2020 to limited categories from within the Kingdom after applying the maximum preventive measures, as well as the availability of health services provided to the population and procedures for examination and detection of cases of infection affected the reduction of cases. The percentage of those examined increased from $14.7 \%$ of the total population at the end of August to about $31.6 \%$ at the end of December 2020.

The Saudi Arabia shares with the State of Bahrain in the form of the infection curve, as they share interest in the procedures for examination, prevention and monitoring of cases of infection, so that it recorded a percentage of examinations that amounted to $138.4 \%$ of the population at the end of December, meaning that the individual was examined more than once to ensure that he was not infected with the virus, which contributed In the slowdown in the growth of infections, while the situation in Egypt and Yemen was different, although the curves of infection in them are also similar to the Saudi Arabia, the slowdown in the growth of cases in Egypt was apparently due to other reasons, the most important of which is the weakness of the state's capabilities in examining the entire population and providing health care within hospitals and places The equipped health isolation, which made it subject about $50 \%$ or more of the infected cases to home isolation, [6] and PCR analyzes are only conducted for those wishing to travel abroad and for some of those who show symptoms of the disease, and the same is the case In Libya, which suffers from a state of political instability and armed conflicts, such as Yemen and Syria.

\section{Morbidity rates in the Saudi Arabia compared to some countries}

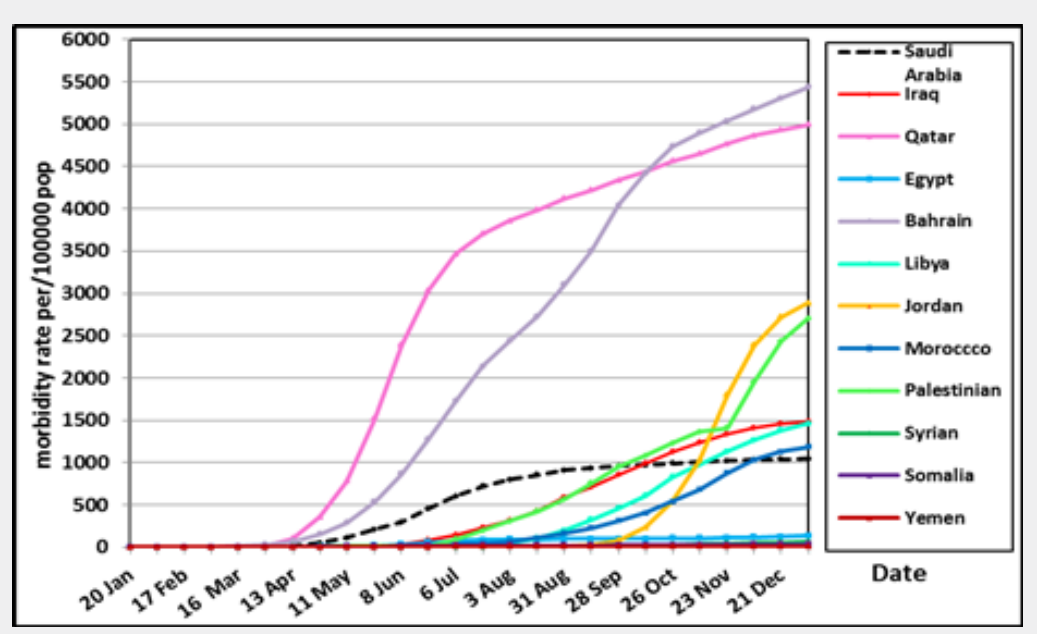

Figure 2: Comparison of Covid19 morbidity rate curve between Saudi Arabia and Arab world during the period from 20 January to 31 December 2020.

Source: researcher calculation depending on: W.H. O., 2020. Coronavirus disease 2019 (COVID-19) Situation Report, I-196. https:// corona-v.com (17 August-31 December 2020). 
The morbidity rate of the epidemic in Saudi Arabia reached about 1041.9 cases / 100,000 people at the end of December 2020 , which is a low rate compared to the world average (1065 / 100,000 people), and the rate in the United States of America (6031 / 100,000 people), and when comparing the morbidity rates with similar ones. From the Gulf countries since the beginning of the first case until 31 December 2020 as shown in Figure 2, It is noted that it's in Bahrain was at the forefront (5431.7 cases / 100,000 people), followed by Qatar (4992.4 cases / 100,000 people), and the reason for this is due to the population's subjection to examination and analysis. It appears that the number of infected people exceeds its neighbors in the Gulf states and the entire Arab world, (the percentage of those examined in Qatar reached 43.1\% of the population), which reveals cases of infection compared to other countries in the region and the world, while the countries of the region and the world where Such as Yemen, Syria, Somalia, and Egypt, with the lowest of morbidity rates, as they recorded, respectively, 7, 29.7, 64.8, 133.5 infected cases per 100,000 population, and they are countries that did not receive tests for the population to detect the presence of the virus.

\section{Development of recovery rates}

As a result of the firmness in taking preventive measures and early detection of infection with the virus that the Saudi Arabia followed in managing the crisis, using some electronic applications to facilitate the examination process, and to provide various treatment services to citizens and residents alike, this was helped by its previous experience in combating the MERS virus that appeared $2012^{1}$, and the equipment with which it was prepared, as a command and control center has been established since 2014, and command and control centers are attached to it to monitor important infectious diseases and emerging diseases that can appear as the new epidemic of Corona [8]. The recovery in the Saudi Arabia reached $97.5 \%$ to become the second Arab country in recovery rates after Qatar $98.3 \%$, and Bahrain is equal with it. On the other hand, recovery rates decreased in countries where morbidity rates are low and death rates are high, such as Syria $46.7 \%$, Libya $65 \%$, Yemen $66.5 \%$, Somalia $76.8 \%$, Egypt $81.6 \%$ Figure 3.

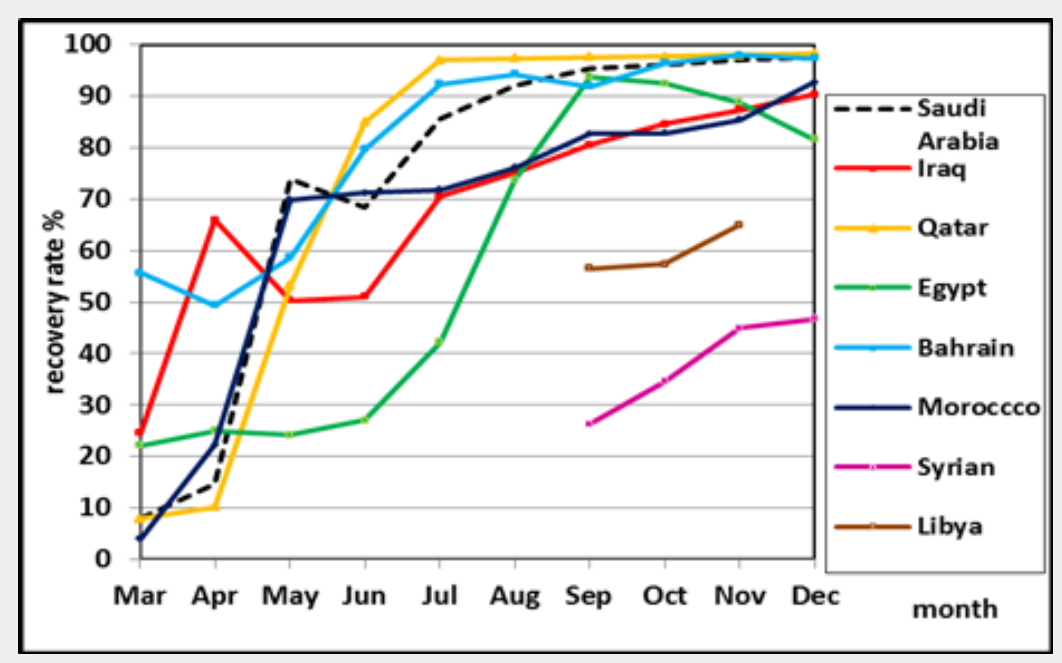

Figure 3: Comparison of Covid19 recovery rate curve between Saudi Arabia and Arab world during the period from March to December 2020.

Source: researcher calculation depending on: https://corona-v.com (31 March-31 December 2020).

\section{Development of fatality rates}

When analyzing the development of the fatality rates in the Saudi Arabia in Figure 4, it turns out that there is a clear stability in the curve of fatality since the beginning of the outbreak of the pandemic, where the percentage started by $0.6 \%$ of the total infected and rose slowly until it reached $1 \%$ in August 2020 and then continued to rise to $1.7 \%$. At the beginning of December, it did not exceed it until the end of the year, which is lower than the global rates, which amounted to $2.2 \%$, and also lower compared to other countries such as Yemen, Sudan, Syria and Egypt, among which the death rate rose to 29.1, 6.3, 6.2, and $5.5 \%$, respectively, which are countries Low morbidity rates are recorded, which confirms their failure to plan to confront the pandemic and preserve their societies from any health crisis they face. In contrast, the fatality rates in the Saudi Arabia were the highest compared to neighboring Gulf countries such as Qatar, United Arab Emirates, Bahrain and Kuwait, where the ratio was, respectively, $0.2,0.3,0.4,0.6 \%$.

${ }^{1}$ The first known of Corona virus MERS-Cov. Which caused of Middle east respiratory syndrome, like Saudi Sars , was in Jeddah city in Saudi Arabia in September 2012 [7]. 


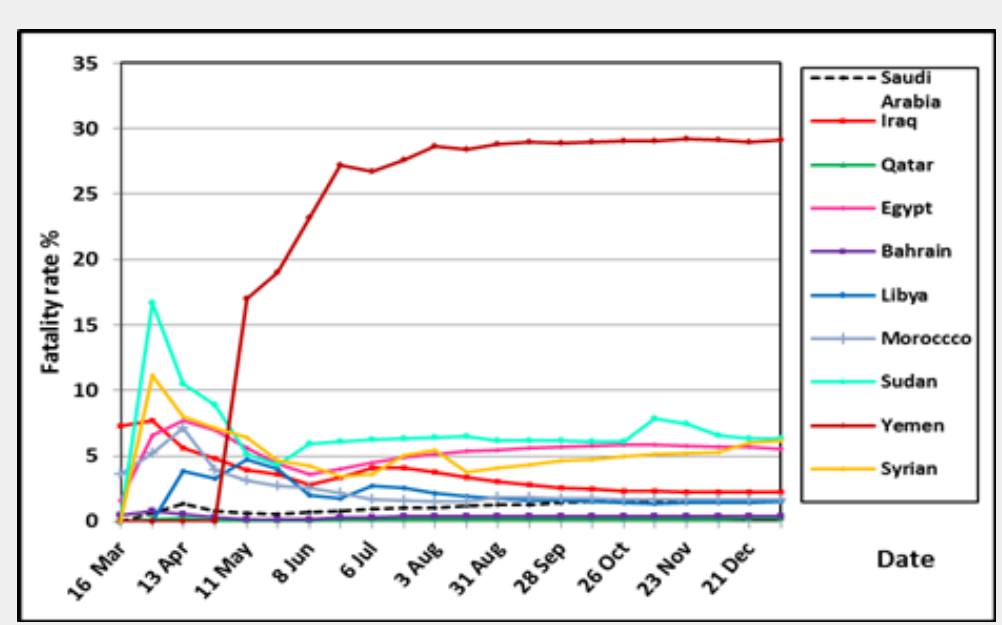

Figure 4: Comparison of Covid19 fatality rate curve between Saudi Arabia and Arab world during the period from 20 January to 31 December 2020.

Source: researcher calculation depending on: W.H. O., 2020. Coronavirus disease 2019 (COVID-19) Situation Report, I-196. https:// corona-v.com (17 August-31 December 2020).

The Spatial Variation of the Covid-19 Epidemic in the Saudi Regions and its Factors

\section{The effect of temperature and humidity}

By following up on the spatial distribution of the epidemic in the regions of Saudi Arabia Figure 5 shows that there is a clear regional variation, while Makkah region, Eastern and Riyadh region recorded the highest cases in the Saudi Arabia until the end of August 2020 with about $71.5 \%$ of the total cases, and it continued to do so until the end of December 2020 was about 69.3\%, the Eastern region, AL-Madinah, and Asir region had the highest morbidity rates, ranging from 1671.2 - 1159.6 cases $/ 100,000$ people at the end of December 2020. While the AlJawf region, the northern border, and the Al-Baha region recorded the lowest cases in August with a rate of $1.7 \%$, and they also continued in the same order until the end of December, despite the increase in cases to reach $2.3 \%$, and the lowest morbidity rates were in the Al-Jawf region, Tabuk and the northern borders region, ranging from 231.3 - 615 cases / 100,000 people until the end of December 2020, and this rate is low compared to the local and international rates, which exceeded about 5,000 cases / 100,000 people, as in neighboring countries such as Bahrain.

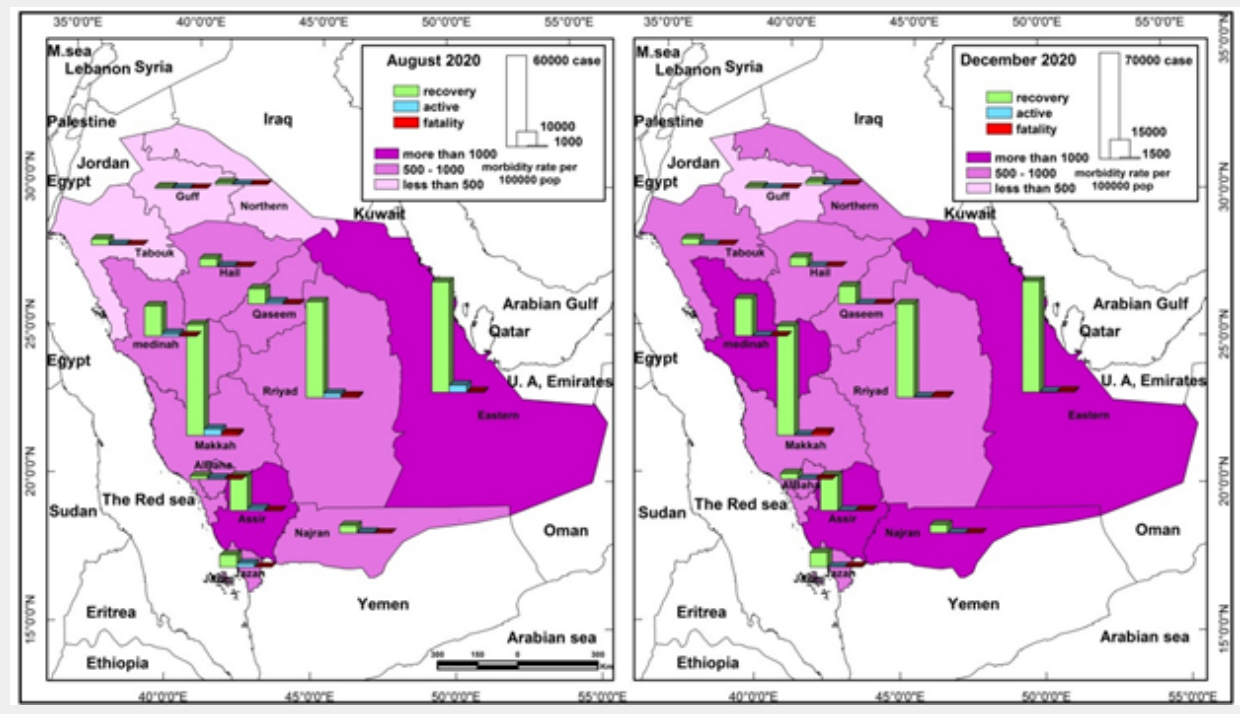

Figure 5: Geographical distribution of covid19 morbidity in Saudi Arabia comparison between August and December 2020. Source: researcher design depending on, https://corona-v.com (31 August-31 December 2020). 
The highest morbidity rates were in the east and southwest of the Saudi Arabia - with the exception of the Jazan region - and extended to include the west of state, which are the regions with the highest temperatures and humidity, while the northern and central regions remained the lowest in morbidity rates, which is consistent with the study published by researchers at the University of Princeton of America, and it was found that the hotter and humid weather did not slow the movement of the virus's spread, and although humidity plays a role in the spread of other Corona viruses, this factor is expected to be limited compared to another factor much more important, which is the very weak collective immunity against the Corona virus [9].

Perhaps the matter here is different due to the circumstances that made the Saudi Arabia as a receiving station for expatriate workers from Southeast Asian countries throughout the year and being an arrival station for the performance of the rituals of Umrah and Hajj, The relationship between temperature and morbidity rates was weak around 0.34 and not significant statistically and was very weak inverse- $(-0.28)$ with relative humidity, it is the similar results of the study about how the temperature and humidity affect the development of Covid-19 in Indonesia, which conclude that the temperature has a positive correlation of 0.3 and that humidity has a positive correlation of $0.2[10,11]$, That means high temperatures and humidity do not cause the virus to grow slower.

\section{Effect of altitude and depression above sea level}

It was noted that the highest region of the Saudi state, the Asir region, recorded high morbidity rates of 1159.6 per 100,000 people, low fatality rates that did not exceed $1.6 \%$, and recovery rates approaching 98\%, which is consistent with the opinions of scientists that people who live at high altitudes of Sea level are less likely to experience the worst effects of the epidemic compared to those who live at sea level, and this is due to the fact that people who live at high altitudes adapt better to low levels of Oxygen in the blood, which is one of the deadly effects of the Corona virus [12], other factors may also interfere, the most important of which is the speed of going for examination and treatment, natural immunity and the availability of medical competencies, which makes the chances of survival higher.

\section{Density population and degree of crowding}

The reason for the high rates of morbidity in the eastern and western regions of Saudi state in general is that it is the most crowded and density populated area, as it includes more than $75 \%$ of the Kingdom's population, and the urbanization rate has exceeded 85\%, and international airports and seaports are concentrated in it due to its being the centers of The economy and industries related to oil, manufacturing and food industries such as the eastern region, and the presence of the holy places in Makkah and AL-Madinah in the west of the Kingdom, although when calculating the correlation coefficient between the general density and morbidity rates was not clear, but seemed very weak $(-0.073)$, as it is not calculated in the general density of areas Inhabited only by people, but calculated on the total area that may be completely devoid of residents. Accordingly, studying the degree of crowding may give more reasonable and realistic results for the relationship of the epidemic to crowded and overcrowded areas [13].

By following Table 2, and Figure 6, we can divide the governorates of Saudi Arabia into several categories to show the extent of variation in the distribution of morbidity rates and the following shows:

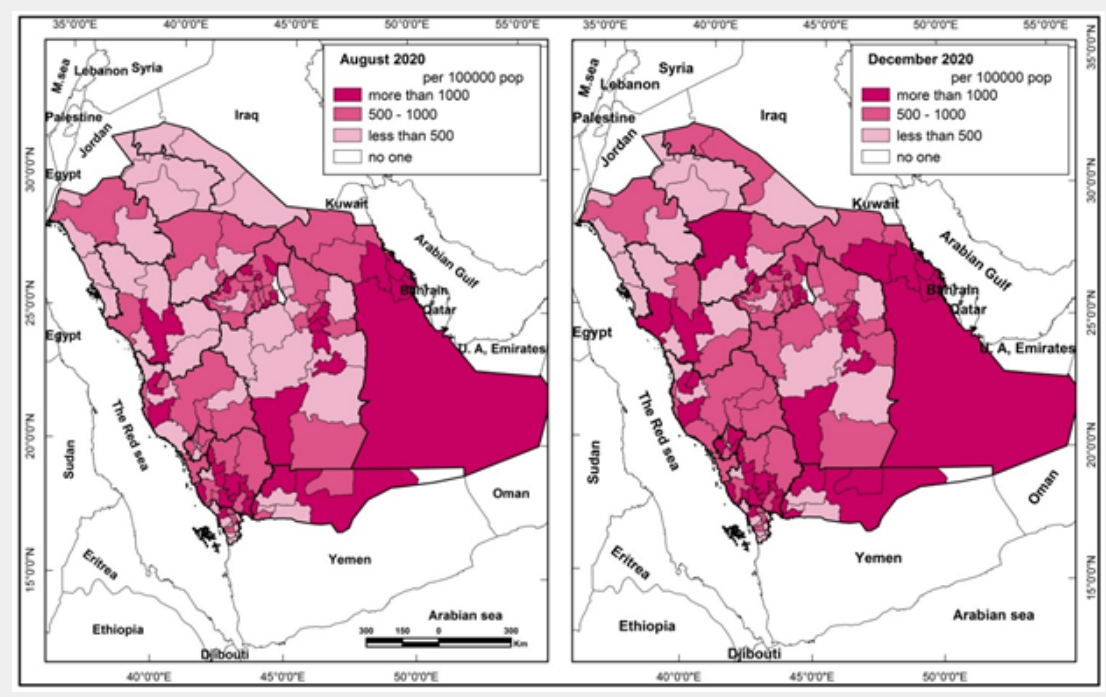

Figure 6: Geographical distribution of covid19 morbidity rate in Saudi Arabia governorate comparison between August and December 2020.

Source: researcher design depending on, https://corona-v.com (31 August-31 December 2020). 


\section{International Journal of Environmental Sciences \& Natural Resources}

Table 2: Classification of Saudi Arabia Governorate according to Covid19 Morbidity rate from the beginning of infection until the end of December 2020

\begin{tabular}{|c|c|c|c|c|c|c|c|c|c|}
\hline \multirow[t]{2}{*}{ Region } & \multicolumn{2}{|c|}{$\begin{array}{c}\text { First } \\
\text { More than } 1000 \\
/ 100.000 \text { people }\end{array}$} & \multicolumn{2}{|c|}{$\begin{array}{c}\text { Second } \\
(500-1000) / 100.000 \\
\text { people }\end{array}$} & \multicolumn{2}{|c|}{$\begin{array}{c}\text { Third } \\
\text { Less than } 500 \\
/ 100.000 \text { people }\end{array}$} & \multicolumn{2}{|c|}{$\begin{array}{c}\text { Fourth } \\
\text { No cases }\end{array}$} & \multirow[t]{2}{*}{$\begin{array}{c}\% \text { From Total } \\
\text { Pop }\end{array}$} \\
\hline & N. & \% Pop & N. & \% Pop & N. & \% Pop & N. & $\%$ Pop & \\
\hline Riyadh & 6 & 1.1 & 8 & 23 & 6 & 1.1 & 0 & 0 & 25.1 \\
\hline Makkah & 3 & 6.6 & 7 & 18.5 & 2 & 0.7 & 0 & 0 & 25.6 \\
\hline AL Madinah & 2 & 5.5 & 2 & 0.4 & 3 & 0.7 & 0 & 0 & 6.5 \\
\hline Qassim & 5 & 1.1 & 4 & 3.2 & 1 & 0.2 & 1 & 0.04 & 4.5 \\
\hline Eastern & 9 & 13.4 & 2 & 1.7 & 0 & 0 & 0 & 0 & 15.1 \\
\hline Asir & 7 & 4.5 & 4 & 2 & 1 & 0.4 & 0 & 0 & 7 \\
\hline Tabuk & 0 & 0 & 1 & 2.1 & 5 & 0.8 & 0 & 0 & 2.9 \\
\hline Ha'il & 1 & 1.5 & 1 & 0.1 & 2 & 0.5 & 0 & 0 & 2.2 \\
\hline Northern & 0 & 0 & 2 & 0.9 & 1 & 0.3 & 0 & 0 & 1.2 \\
\hline Jazan & 2 & 0.9 & 3 & 1 & 9 & 3.1 & 0 & 0.01 & 4.9 \\
\hline Najran & 4 & 1.6 & 0 & 0 & 3 & 0.2 & 1 & 0 & 1.8 \\
\hline Al Baha & 3 & 0.6 & 3 & 0.5 & 1 & 0.4 & 0 & 0 & 1.5 \\
\hline Al-Jawf & 0 & 0 & 0 & 0 & 3 & 1.6 & 0 & 0 & 1.6 \\
\hline
\end{tabular}

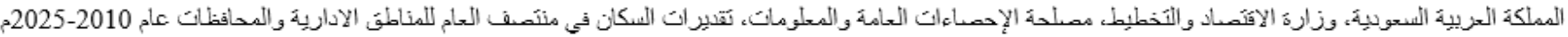

Source: researcher calculation depending On : attribute table figure (6),

The morbidity rates increased to more than 1,000 cases per 100,000 people until the end of December 2020 in about 42 governorates (an increase of $23.8 \%$ in the number of governorates compared to the end of August 2020). These governorates represent about $35.6 \%$ of the total governorates of the Saudi Arabia, inhabited by about $36.7 \%$ of the population, comprising $56.1 \%$ of the total patients, and it is noticeable that these governorates were concentrated in the eastern, western, southwestern and central sectors of the Saudi Arabia, and the morbidity rates in seven governorates exceeded 2000 cases per100,000 people, three of them in the eastern region is $\mathrm{Al}-$ Nairiyah governorate ( which consider is the first governorate in the morbidity rate 2421 cases / 100,000 people), Hofuf, Abqaiq, and Baysh governorate in the Jazan region, Oyoun Al-Jawa in the Qassim region, Huraymila in the Riyadh region, and Dhahran Al-Janoub in the Asir region, and this category included seven metropolises of the administrative regions, The thirteen in the Saudi Arabia are Jazan, Abha, Dammam, Makkah, AL-Madinah Hail, Najran, as well as the most important industrial cities in the Eastern Province such as Ras Tanura, Khobar, and Jubail.

The reason behind this distribution Perhaps is that these areas are the most crowded regions of the state, and millions of arrivals from international airports flock to them from different countries. The total number of passengers coming from outside until the end of 2019 , i.e. directly before the announcement of Covid 19 and the decision to stop air traffic, amounted to more than 48 million Passengers [14], the share of King Abdulaziz International Airport in Jeddah was more than 23 million passengers, followed by King Khalid Airport in Riyadh with more than 12 million passengers, and Prince Muhammad bin Abdulaziz Airport in the city with more than 5 million passengers, then King Fahd Airport in Dammam, about 4.8 million passengers, then the number of passengers coming from abroad decreases in the rest of the Kingdom's regions, while there are no international airports in Najran, the northern border, and Al Baha, which made them the least regions in the number of infections. When calculating the correlation coefficient between the number of passengers coming to Saudi lands from outside and the number of people infected with Covid 19, as shown in Table 3, the positive correlation was (0.71).

The morbidity rates ranged from 500 - 1000 cases / 100,000 people until the end of December 2020 in about 37 governorates, with an increase of $5.4 \%$ in the number of governorates until the end of August, which represents $31.3 \%$ of the total governorates of the Saudi Arabia and includes about 53\% of the total population of the country. And about $41 \%$ of the total cases of infection, and they are distributed over the parts of the state, especially the eastern, southern and western parts, topped by the governorates of Taif (Makkah region), Sarat Abidah (Asir region), Hafr Al-Batin (Eastern region), Riyadh (Riyadh region), and this category included the rest of the cases. The metropolises of the administrative regions except for Al-Baha (Al-Baha region) and Sakaka (Al-Jawf region) . In the study, it was noted that these areas represent a link between the governorates of the first category together, where the population is considered more exposed to risk factors. 


\section{International Journal of Environmental Sciences \& Natural Resources}

Table 3: Passengers of international airports in Saudi Arabia 2019 and Covid19 cases 2020.

\begin{tabular}{|c|c|c|}
\hline Airports & Covid19 Cases & Passengers (International) \\
\hline King Khalid International Airport (Arriyad) & 60286 & 12408372 \\
\hline King Abdulaziz International Airport(Jiddah) & 34815 & 23366260 \\
\hline King Fahd International Airport (Addammam) & 20128 & 4847032 \\
\hline Prince Mohammad Bin Abdulaziz International Airport (Almadinah) & 22931 & 5781716 \\
\hline Taif International Airport & 12505 & 360273 \\
\hline Abha Airport & 8070 & 444889 \\
\hline Ha'il Airport & 6510 & 165934 \\
\hline King Abdullah Bin Abdulaziz Airport (Jazan) & 3890 & 145554 \\
\hline Prince Naif Bin Abdulaziz Airport (Buraydah) & 5982 & 674613 \\
\hline Prince Sultan Bin Abdulaziz Airport (Tabuk) & 4159 & 185961 \\
\hline Prince Abdulmohsin Bin Abdulaziz Airport (Yanbu) & 5425 & 253278 \\
\hline Al-Jawf Airport (Sakaka) & 818 & 122005 \\
\hline Al Ahsa Airport & 30222 & 24444 \\
\hline Nejran & 4461 & - \\
\hline Arar & 1740 & - \\
\hline Albaha & 573 & - \\
\hline Total & & 48780331 \\
\hline
\end{tabular}

Source: researcher design depending on: https://corona-v.com (31 Decamber2020), General Authority of Civil Aviation 2019.

The morbidity rates decreased to less than $500 / 100,000$ people in about 37 governorates, representing $31.3 \%$ of the total governorates, and these areas include only $9.9 \%$ of the population, about $2.9 \%$ of the total cases, led by Shaqra governorate in the Riyadh region at a rate of $490.3 / 100,000$ people, in When it decreased to 5.1/100,000 in Al-Jumoom Governorate, Makkah region, this may be due to the fact that the primary health systems in these areas do not help in detecting the disease, shared by the distance of these governorates and their isolation from centers of population gathering and visitors traveling to them from different countries of the world. Perhaps the dependence of the local population on folk medicine in medicine ${ }^{2}$ played a role in the low rates of infection.

The governorates in which no cases were recorded included the Shammasiya governorate in the Qassim region, and Al-Kharkhir in the Najran region. It is noted in these aspects that they are also tend to move away from the metropolises of the administrative regions and the large-populated governorates and that they are dislocated, as it includes only $0.1 \%$ of the population, so that the governorate of Al-Kharkhir Its presence as a governorate was canceled due to the absence of any services there.

\section{Geographical variations in recovery and fatality rates}

Recovery rates increased to more than $90 \%$ in all governorates of the Saudi Arabia, as shown in Figure 7 between the months of August and December 2020, with the exception of some governorates of the northern regions and governorates of the central regions, most of which recorded the highest fatality rates and the lowest morbidity rates.

Figure 8, shows the distribution of covid19 fatality rate in the Saudi Arabia during August to December 2020, the highest fatality rate were concentrated in the north of and some governorates of the southwest, which are border governorates and the percentages continued to increase and expanded to remain concentrated in the north Al-Baha governorate (Emirate of Al-Baha region) recorded the highest fatality rates until the end of December 2020, 11.2\% of the total number of infected, followed by Al-Harth, Al-Ardah, Damad, Sabya, Al-Darb, Jizan (Jazan region) 11.1, 10.2, 7.2, 6.3, 5.6, 5.1\%, respectively, Sakaka Governorate 5.2\% (Al-Jawf region), Arar Governorate 4.1\%, Rafha 3.1\% (Northern border).

This may be due to the fact that these governorates are areas that lack medical competencies compared to the Riyadh region, Eastern region, Makkah and AL-Madinah, where doctors tend to concentrate in major cities in particular because they provide better opportunities for work and study, and then recovery cases are delayed and fatality rates are high, and confirms that the lack of The presence of any private hospitals in the Al-Jouf region and the northern borders, and only one hospital in the Al-Baha region (not in the Emirate of the region) and one in the Jazan region, and the

${ }^{2}$ The phenomenon of medication using folk medicine is considered one of the important phenomena that resonates with Arab peoples in general and members of Saudi society in particular, and its practice is still witnessing a steady spread in various social circles, because of its relationship to customs inherited through generations. Medication among the residents of the Qassim region that the percentage of people using traditional medicine in the treatment of diseases reaches about $99 \%$ of the sample [15]. 
decrease in the number of private clinics and their concentration in the headquarters of the Emirate of the region, in contrast to the presence of 37 private hospitals in the city of Riyadh alone, and in the Makkah region 44 private hospitals They are concentrated in the cities of Jeddah and Makkah, and in the Eastern Province 28 private hospitals spread over most of its governorates, and 12 private hospitals in the Madinah region distributed over Madinah, Taif and Yanbu [16], and the morbidity rates in Al-Harth and AlArdah governorates (Jazan region) drop to 155,161 cases per 100,000 people, respectively, while the fatality rate in them rises to $11,10 \%$.

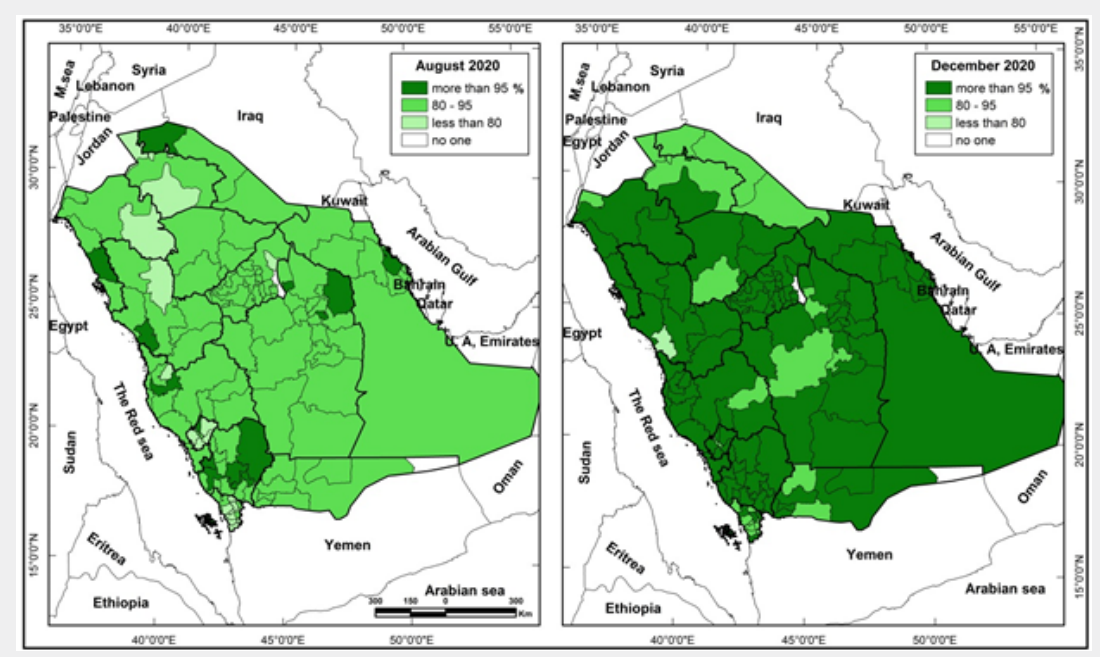

Figure 7: Geographical distribution of covid19 recovery rate in Saudi Arabia governorate comparison between August and December 2020.

Source: researcher design depending on, https://corona-v.com (31 August-31 December 2020).

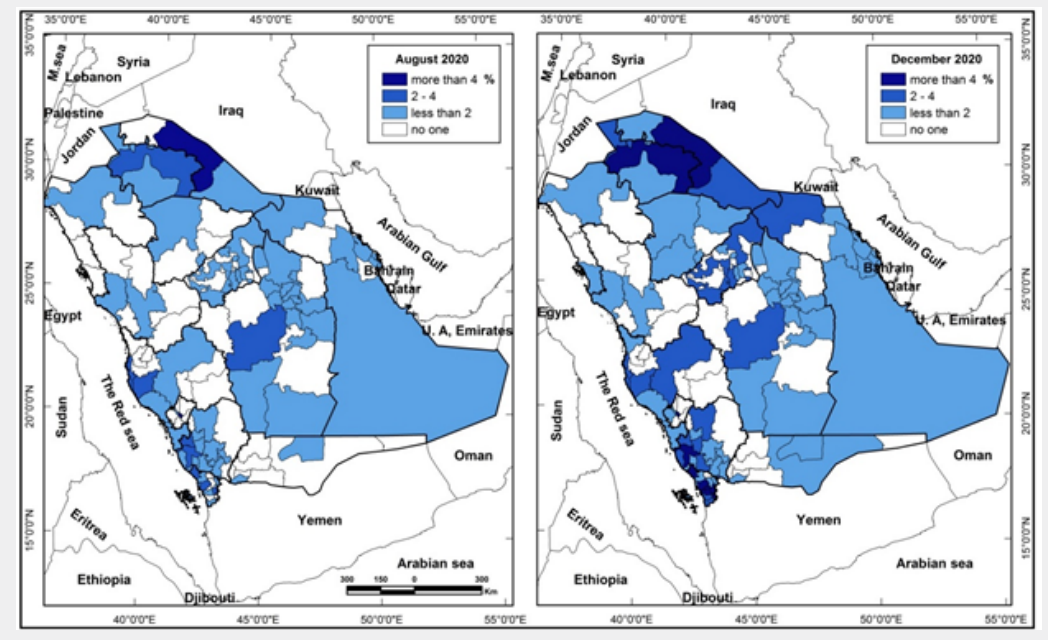

Figure 8: Geographical distribution of covid19 fatality rate in Saudi Arabia governorate comparison between August and December 2020.

Source: researcher design depending on, https://corona-v.com (31 August-31 December 2020).

\section{The human environment and its relationship to} morbidity and Fatality rates

Through the previous presentation, it becomes clear that there are many factors that raise the degree of risk of infection with the Covid19 and other diseases, and in this part the impact of some of these factors will be studied, such as health, social and environmental factors that may be more related to the rates of morbidity and fatality with pandemic in the thirteen regions of the Saudi Arabia - They are twenty-nine variables, as illustrated in Appendix (1) - using the stepwise regression analysis method, where the variables that explain the largest value of the variance, respectively, according to their importance, enter into this statistical analysis, and then exclude the variables that have no statistical significance. 
When applying a stepwise regression analysis of the independent variables, Appendix (1), to test their impact on the dependent variable (morbidity rate) until the end of August 2020 , it was found through the matrix of correlations between independent variables and the dependent variable and the Sig. value of the correlation that the correlation coefficient between the morbidity rate of epidemic and the variable of the highest concentration of sulfur dioxide gas (0.72), percentage of the population practicing sports (0.54), the morbidity rate of Amoebic dysentery (0.79), and the morbidity rate of salmonella (0.75), is a direct correlation between the mean and strength, and the variables of the hospital beds rate $/ 100,000$ population $(-0.69)$, the isolation beds rate $/ 100,000$ pop. $(-0.52)$, the intensive care beds rate $/ 100,000$ pop. $(-0.73)$, the physicians rate $/ 100,000$ pop. $(-0.66)$, the chest physicians rate $/ 100,000$ pop $(-0.66)$, and E.N.T physicians rate $/ 100,000$ pop. $(-0.65)$, , and the Radiology physicians rate $/ 100,000$ pop. (-0.58), Laboratory physicians rate
$/ 100,000$ pop. (-0.62), and a nursing staff /physicians (-0.55), which is an inverse correlation between the mean and the strong with significant levels ranging from (0.001-0.036), while the rest of the variables are not statistically significant.

However, the variables that were included in the stepwise regression analysis and were statistically significant at the level (0.05), were only the variable morbidity rate of Amoebic dysentery per 100,000 pop., where it came at the forefront of the variables included in the regression analysis and explained the square of the correlation coefficient (R -Sq.) with a value of 0.629 (i.e. $62.9 \%$ ), then followed by the variable of the isolation beds rate per 100,000 pop, where they explained together an amount of $89.5 \%$ (Table 4), while the rest of the variables were excluded as the partial correlation between them. There is a weak and not statistically significant correlation between the morbidity rate, and accordingly we have an equation for the stepwise regression as follows: $\mathrm{Y}_{1}=841.378+37.551 \mathrm{X}_{26}-29.200 \mathrm{X}_{14}$.

Table 4: Stepwise regression analysis of the effect of independent variables on the dependent variable (morbidity rate of Covid19).

\begin{tabular}{|c|c|c|c|c|c|c|}
\hline Dependent Variable & Variable No. & Independent Variables Entered & R-sq & Std. (B) & (t) & sig \\
\hline \multirow{2}{*}{$\begin{array}{l}\text { Morbidity rate until } \\
\text { August } 2020\left(Y_{1}\right)\end{array}$} & $\mathbf{X}_{26}$ & $\begin{array}{c}\text { morbidity Rate of Amoebic dysentery /100000 } \\
\text { population }\end{array}$ & 0.629 & 37.551 & 4.317 & 0.001 \\
\hline & $\mathrm{X}_{14}$ & Isolation beds rate /100000 Population & 0.895 & -29.2 & -5.046 & 0 \\
\hline \multirow{2}{*}{$\begin{array}{l}\text { Morbidity rate until } \\
\text { December } 2020\left(\mathrm{Y}_{4}\right)\end{array}$} & $\mathbf{X}_{26}$ & $\begin{array}{l}\text { morbidity Rate of Amoebic dysentery /100000 } \\
\text { population }\end{array}$ & 0.506 & 36.848 & 4.535 & 0.006 \\
\hline & $X_{14}$ & Isolation beds rate /100000 Population & 0.753 & -30.775 & -3.163 & 0.01 \\
\hline
\end{tabular}

Source: In preparing this table, the researcher relied on the results of stepwise regression that she conducted using the SPSS program when entering data for Appendix (1) variables.

Considering that $\mathrm{Y}$ is the value of the predicted dependent variable, $\mathrm{X}$ is the independent variables shown in Appendix (1), and the constant is equal to (841.378).

And when the stepwise regression analysis of the independent variables was re-analyzed to see their impact on the dependent variable, the morbidity rate of the epidemic, but until the end of December 2020, the result did not differ much, as all the independent variables came out of the analysis except for the variable rate of amoebic dysentery per 100,000 pop, and it came to the fore of the included variables. In the regression analysis, it alone explained an amount of $50.6 \%$, then followed by the variable of the isolation beds rate per 100,000 pop., where they explained together an amount of $75.3 \%$.

Perhaps the decrease in the explained percentage upon reanalysis at the end of December is due to the overlap of other factors, such as some social behaviors and habits related to social distancing, concern for personal hygiene and wearing masks, and accordingly, the regression is significant, and therefore there is a relationship between the dependent variable and the independent variables, and that the variables $\mathrm{X}_{26}, \mathrm{X}_{14}$ are the two that added an explanation Essentially for the variance in the dependent variable, the best regression line equation between the variables is:
$Y_{4}=704.233+36.892 X_{26}-30.775 X_{14}$

It is worth noting that the standard regression coefficient of the two variables, one of them is positive, indicates that the higher of morbidity amoebic dysentery, corelated with the higher of Corona morbidity rate, and the other is negative, that is, the decrease in the rate of isolation beds increases the Corona morbidity rate. Therefore, it was necessary to pay attention to the areas most exposed to risk factors and to provide services and treatment to the population of the areas. fair remote. The Lancet, Latest global disease estimates reveal perfect storm of rising chronic diseases and public health failures fueling COVID-19 pandemic [17].

When applying a stepwise regression analysis of the independent variables, Appendix (1), to see their impact on the dependent variable, the fatality rate in the epidemic until the end of August 2020, all the independent variables were not statistically significant at the level $(0.05)$, except for the variable chest physicians rate $/ 100,000$ pop, Where it came at the forefront of the variables included in the regression analysis and explained the unit rate of $52.1 \%$, followed by the average wind speed variable, which together explained an amount of $72.8 \%$ of the variance in the fatality rate Table 5. 


\section{International Journal of Environmental Sciences \& Natural Resources}

Table 5: Stepwise regression analysis of the effect of independent variables on the dependent variable (fatality rate of Covid19).

\begin{tabular}{|c|c|c|c|c|c|c|}
\hline Dependent Variable & Variable No. & Independent Variables Entered & R-sq & Std.(B) & (t) & Sig \\
\hline \multirow{2}{*}{$\begin{array}{l}\text { Fatality rate until August } \\
\qquad 2020\left(Y_{2}\right)\end{array}$} & $\mathbf{X}_{17}$ & Chest physicians rate / 100000 Population & 0.521 & 0.688 & 3.895 & 0.003 \\
\hline & $\mathbf{X}_{3}$ & average Wind speed & 0.738 & 0.434 & 2.876 & 0.016 \\
\hline \multirow{3}{*}{$\begin{array}{l}\text { Fatality rate until December } \\
\qquad 2020\left(Y_{5}\right)\end{array}$} & $X_{17}$ & Chest physicians rate / 100000 Population & 0.337 & 0.761 & 3.35 & 0.009 \\
\hline & $X_{11}$ & Density & 0.781 & 0.025 & 5.955 & 0 \\
\hline & $\mathbf{X}_{23}$ & Nursing staff / physicians & 0.871 & 1.527 & 2.511 & 0.033 \\
\hline
\end{tabular}

Source: In preparing this table, the researcher relied on the results of stepwise regression that she conducted using the SPSS program when entering data for Appendix (1) variables.

When the stepwise regression analysis of the independent variables was re-analyzed to see their impact on the fatality rate, but until the end of December 2020, the result differed, as the independent variables included in the regression line equation were statistically significant at the level (0.05), the chest physicians rate $/ 100,000$ pop variable, Where it came in the introduction and explained the (R -Sq.) of 0.337 (ie, 33.7\%), then followed by the population density variable, where they explained together an amount of $78.1 \%$, and finally the variable nursing staff / physicians, and they explained the three together $87.1 \%$, and therefore the regression is significant and therefore there is A relationship between the dependent variable and the independent variables, and the variables $\mathrm{X}_{17}, \mathrm{X}_{11}, \mathrm{X}_{23}$ are the two who added a fundamental explanation for the variance in the dependent variable, and accordingly, the regression equation is as follows: $Y_{5}=-2.967+0.761 X_{17}+0.25 X_{11}+1.527 X_{23}$

Considering that $\mathrm{Y}$ is the value of the predicted dependent variable, which is the fatality rate of Covid19, $\mathrm{X}$ is the independent variables shown in Appendix (1), and the constant is equal to $(-2.967)$, and it is worth noting that the standard regression coefficient of the variables was positive, which indicates that when these variables have increased the fatality rate increase too, and the only explanation is the delay of cases in receiving treatment, which causes the inability to save them even with the increase in the number of doctors and the nursing staff supporting them, and that medical efficiency is the measure in the decline in fatality rates, not numerical efficiency alone [18-23].

\section{Conclusion}

Protecting people from epidemics and diseases comes at the top of the priorities set by the World Health Organization and ministries of health in all countries of the world to improve the health of peoples, and the crisis of the spread of the new Corona epidemic is one of the most important health challenges facing all countries of the world.

This study comes to analyze the environmental factors affecting the occurrence of the epidemic. In the Saudi Arabia, the study has proven that the morbidity rate curve quickly rose to reach its peak, exceeding 100,000 during the first three months, and then the curve began to slow growth and relative stability, due to the application of preventive measures and the closure of airports. And the Social Distance, which was strictly applied by the Kingdom to stop the spread of the epidemic, which led to a decrease of morbidity rate at the end of December, compared to the global average, and recovery rates increased until it reached 97.5\% to become the second Arab country.

The study showed that the most crowded governorates in which morbidity rates increased, which are that were concentrated in the eastern, western, southwestern and central sectors of the Saudi Arabia, and recovery rates rose to more than $90 \%$ in all governorates between August and December 2020, except for some governorates of the northern, central and southwestern regions, most of which recorded the highest fatality rates, and the lowest rates of infection. Al-Baha governorate recorded the highest fatality rate until the end of 2020.

Saudi Arabia has succeeded through many procedures and applications that helped it to identify and reduce rates of disease through programs and applications on mobile phones that locate the citizen accurately and track them through satellites, including the Tawakkalna application which tracks each individual and determines his condition. The program has added a feature to manage markets and malls, which is to sort people before coming to the mall, to protect the people present, the application is applied successfully, and these positives helped reduce cases of infection at the level of capital of Riyadh and the governorates.

The study recommends alerting the Saudi authorities in the audio-visual media to the need for individuals, whether citizens or residents, to adhere to social distancing measures as much as possible and not to approximate even in the family zone and to take all precautionary measures in living and make this healthy social behavior one of the basics that all individuals are keen to follow regardless .

Conducting more studies to find out the reasons behind the high fatality rates in the governorates with low rates of morbidity.

The study also recommends intensifying the follow-up of the responsible health authorities for arrivals, especially from Southeast Asia, India, in which new mutated cases appear from time to time that may not appear at the beginning of infection, and to make those coming from these areas subject to observation in safety places. 


\section{Appendix (1)}

\begin{tabular}{|c|c|c|c|c|c|c|c|c|c|c|c|c|c|c|c|c|c|}
\hline $\begin{array}{l}\text { Vari- } \\
\text { able } \\
\text { No. }\end{array}$ & $Y_{1}$ & $\mathbf{Y}_{2}$ & $\mathbf{Y}_{3}$ & $\mathbf{Y}_{4}$ & $Y_{5}$ & $Y_{6}$ & $X_{1}$ & $\mathbf{X}_{2}$ & $\mathbf{X}_{3}$ & $\mathrm{X}_{4}$ & $X_{5}$ & $X_{6}$ & $X_{7}$ & $\mathrm{X}_{8}$ & $X_{9}$ & $X_{10}$ & $X_{11}$ \\
\hline 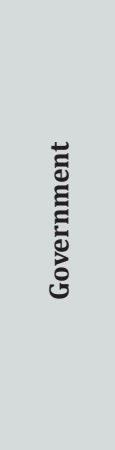 & 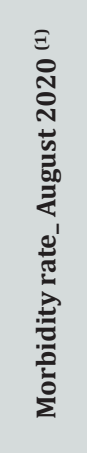 & 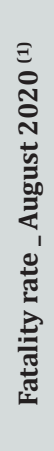 & 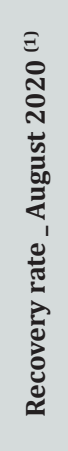 & 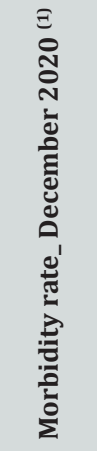 & 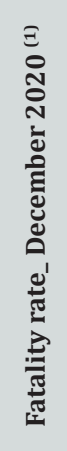 & 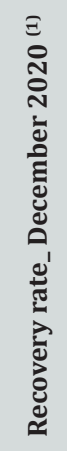 & 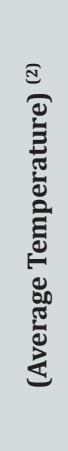 & 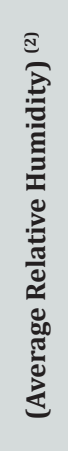 & 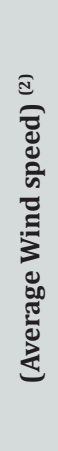 & 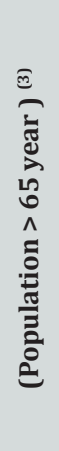 & 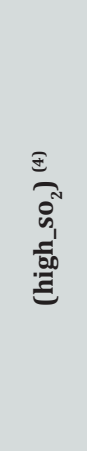 & 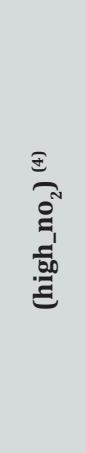 & 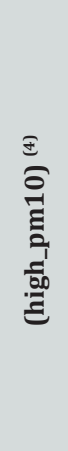 & 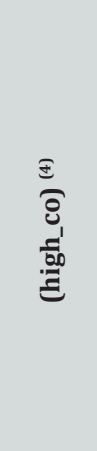 & 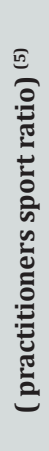 & 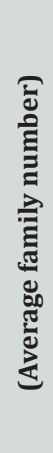 & 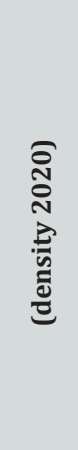 \\
\hline Riyadh & 770.2 & 1.6 & 94.4 & 855.6 & 1.67 & 97.7 & 27.5 & 32 & 6.5 & 2.4 & 315.5 & 479.9 & 998 & 38937 & 14 & 5.6 & 23.1 \\
\hline Makkah & 886.4 & 2 & 92.5 & 982.4 & 2.69 & 96.9 & 28.6 & 46.2 & 4.7 & 3.6 & 196.5 & 170 & 987 & 21724 & 23 & 5 & 65.6 \\
\hline $\begin{array}{l}\text { AlMadi- } \\
\text { nah }\end{array}$ & 965.2 & 0.6 & 91.4 & 1307.5 & 0.55 & 98.6 & 29.1 & 36.9 & 4.5 & 4.1 & 132 & 296 & 983 & 28664 & 19 & 5.5 & 15.2 \\
\hline Qassim & 747.6 & 0.9 & 87.5 & 907.8 & 1.39 & 97.4 & 26.6 & 43.8 & 4.5 & 3.2 & 111.5 & 158 & 1121 & 54970 & 15 & 5.8 & 21.2 \\
\hline Eastern & 1493 & 0.6 & 93.3 & 1671.2 & 0.96 & 98.6 & 28 & 38.1 & 6.5 & 2.3 & 471 & 503 & 994 & 38387 & 20 & 6.1 & 9.8 \\
\hline Asir & 1013 & 0.5 & 93.8 & 1159.6 & 1.57 & 97.8 & 22.4 & 44.5 & 4.3 & 4.7 & 180 & 433 & 926 & 4065.4 & 16 & 5.6 & 30.2 \\
\hline Tabuk & 435.1 & 1.4 & 88.9 & 503.9 & 1.65 & 97 & 25.3 & 48.7 & 4.5 & 2.6 & 111.1 & 410 & 960 & 17212 & 16 & 5.8 & 7.4 \\
\hline Ha'il & 755.6 & 0.8 & 92.4 & 967.3 & 1.78 & 96.9 & 23.6 & 34.8 & 4 & 3.9 & 238.2 & 235 & 961 & 11692 & 18 & 6.3 & 6.3 \\
\hline $\begin{array}{l}\text { North- } \\
\text { ern }\end{array}$ & 368 & 3.7 & 88 & 615.6 & 3.53 & 89.2 & 23.3 & 44.6 & 6.7 & 3.1 & 111.1 & 410 & 960 & 17212 & 13 & 7.3 & 3.9 \\
\hline Jazan & 622.7 & 1.2 & 76 & 702 & 3.83 & 94.8 & 31.3 & 65 & 5 & 4.6 & 99.7 & 105 & 993 & 25537 & 14 & 6.6 & 133.2 \\
\hline Najran & 853.6 & 0.2 & 90.1 & 1015.3 & 1.01 & 97.7 & 27.2 & 28.7 & 3.5 & 3.4 & 99.7 & 105 & 993 & 25537 & 20 & 5.8 & 4.9 \\
\hline Al Baha & 551.2 & 0.9 & 75 & 866.5 & 1.46 & 95.9 & 23.7 & 48.4 & 4 & 5.5 & 99.7 & 105 & 993 & 25537 & 14 & 5.4 & 43.3 \\
\hline Al-Jawf & 183.7 & 2.3 & 82.9 & 231.3 & 4.25 & 93.6 & 22.8 & 38.2 & 5 & 2.8 & 111.1 & 410 & 960 & 17212 & 17 & 6.1 & 6.6 \\
\hline
\end{tabular}

Source: researcher calculation depending on:

1. WHO (2020) Coronavirus disease 2019 (COVID-19) Situation Report, l-196.

2.

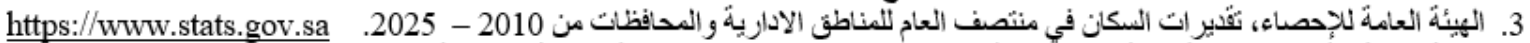

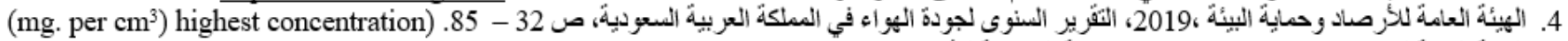

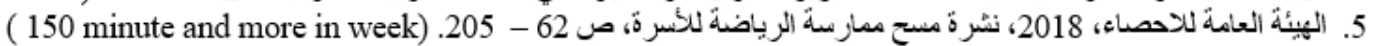




\begin{tabular}{|c|c|c|c|c|c|c|c|c|c|c|c|c|c|c|c|c|c|c|}
\hline $\begin{array}{c}\text { Variable } \\
\text { No. }\end{array}$ & $X_{12}$ & $\mathrm{X}_{13}$ & $\mathrm{X}_{14}$ & $\mathbf{X}_{15}$ & $X_{16}$ & $X_{17}$ & $X_{18}$ & $X_{19}$ & $X_{20}$ & $\mathbf{X}_{21}$ & $X_{22}$ & $X_{23}$ & $\mathbf{X}_{24}$ & $\mathbf{X}_{25}$ & $\mathbf{X}_{26}$ & $\mathbf{X}_{27}$ & $\mathbf{X}_{28}$ & $\mathbf{X}_{29}$ \\
\hline 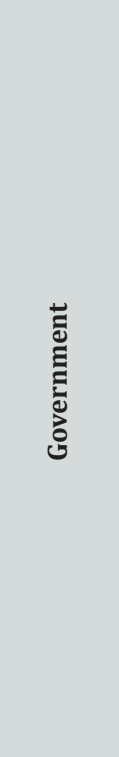 & 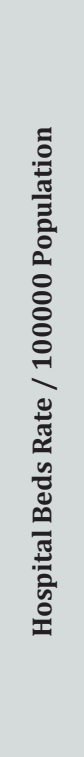 & 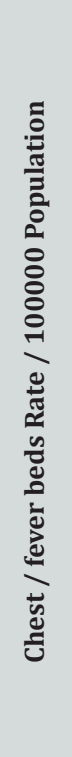 & 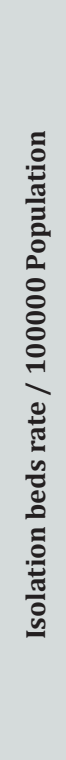 & 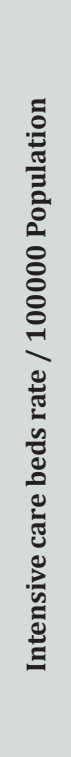 & 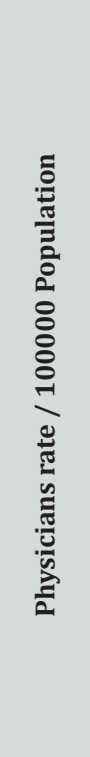 & 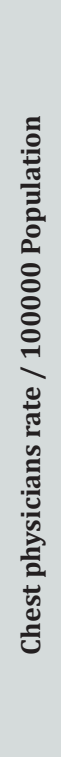 & 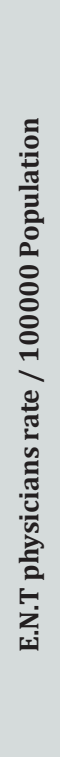 & 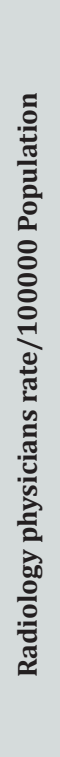 & 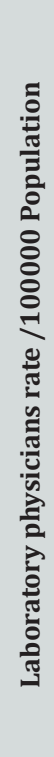 & 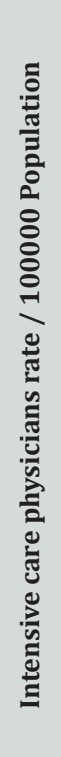 & 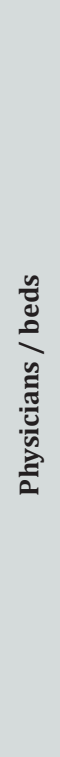 & 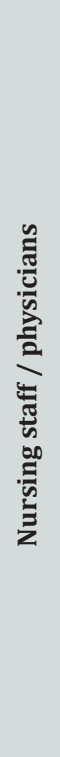 & 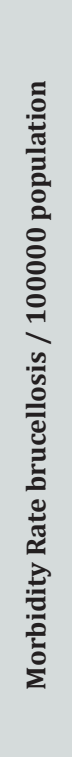 & 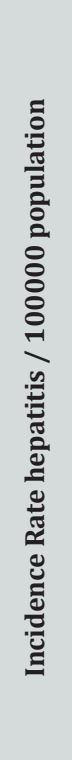 & 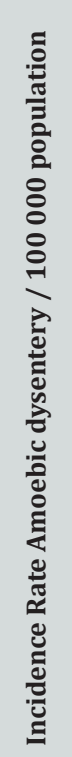 & 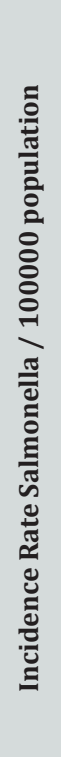 & 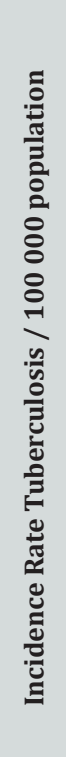 & 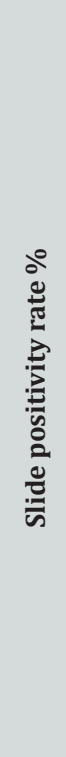 \\
\hline Riyadh & 98.8 & 2.9 & 2.8 & 12.3 & 104.2 & 0.5 & 1.1 & 2.1 & 1.5 & 2 & 1.1 & 2.3 & 5.9 & 19.8 & 1.2 & 7.8 & 5.8 & 0.06 \\
\hline Makkah & 100 & 0.7 & 6.9 & 12.9 & 107.7 & 0.8 & 1.4 & 3 & 2.4 & 4.3 & 1.1 & 1.8 & 11.5 & 43.1 & 9.1 & 7.4 & 10.7 & 0.46 \\
\hline $\begin{array}{c}\mathrm{Al} \\
\text { Madinah }\end{array}$ & 145.9 & 3 & 5.7 & 18.2 & 131.8 & 1.1 & 2.1 & 3.6 & 2.9 & 6.6 & 0.9 & 2.1 & 14.8 & 29 & 2.1 & 5.4 & 5.5 & 0.23 \\
\hline Qassim & 191 & 0.9 & 6 & 21.3 & 156.5 & 1.1 & 2.2 & 5.1 & 4.7 & 5.8 & 0.8 & 2.3 & 20.4 & 20.2 & 3.4 & 0.3 & 2 & 0.11 \\
\hline Eastern & 123.8 & 0.7 & 7.7 & 11.3 & 115.9 & 0.4 & 1.6 & 2.6 & 2.5 & 3.7 & 0.9 & 2 & 9.1 & 33.8 & 21.9 & 18 & 5.5 & 0.08 \\
\hline Asir & 134.6 & 1.6 & 7 & 15.9 & 108.1 & 1 & 1.8 & 2.9 & 3.2 & 4.4 & 0.8 & 1.9 & 17.2 & 26.5 & 13.4 & 1 & 3.6 & 0.37 \\
\hline Tabuk & 185.1 & 1.8 & 11.6 & 26.8 & 146.6 & 1.2 & 2.3 & 3.4 & 3.4 & 8 & 0.8 & 2.1 & 15.1 & 17.2 & 1 & 2.4 & 2.5 & 0.33 \\
\hline Ha'il & 249.6 & 1.3 & 11.2 & 18.8 & 174.5 & 1.7 & 2.8 & 5.7 & 5.1 & 3.9 & 0.7 & 2.1 & 51 & 6.5 & 1.3 & 1.5 & 1.5 & 0.39 \\
\hline $\begin{array}{l}\text { North- } \\
\text { ern }\end{array}$ & 341.7 & 12.1 & 17.1 & 38.4 & 247.5 & 3.5 & 3.8 & 8 & 6 & 5.8 & 0.7 & 2.5 & 47.2 & 24.4 & 1 & 0.3 & 3.5 & 0.99 \\
\hline Jazan & 130.8 & 2.9 & 8.1 & 10.6 & 113.5 & 0.8 & 2 & 4.2 & 2.6 & 4.4 & 0.9 & 2 & 0.9 & 51.2 & 0.6 & 1.9 & 10.6 & 0.42 \\
\hline Najran & 206.1 & 1.6 & 21.1 & 23.6 & 200.2 & 1.3 & 3.2 & 7.8 & 5.4 & 9.8 & 1 & 2.1 & 49.9 & 35.5 & 14.7 & 6.2 & 4 & 0.11 \\
\hline Al Baha & 228 & 3.9 & 9.8 & 19 & 194.2 & 0.8 & 2.9 & 6.3 & 8 & 7.6 & 0.9 & 1.7 & 11.4 & 25.8 & 0.6 & 4.3 & 3.1 & 0.09 \\
\hline Al-Jawf & 331.4 & 0.4 & 21.1 & 48.4 & 236.4 & 2.7 & 3.8 & 7.3 & 8.7 & 9.3 & 0.7 & 3 & 18.9 & 15.3 & 1.1 & 1.1 & 4.2 & 0.03 \\
\hline
\end{tabular}

Source: Researcher calculation depending on:

https://www.moh.gov.sa/Ministry/Statistics/book/Pages/default.aspx. 
References

1. https://corona-v.com

2. https://www.worldometers.info/coronavirus/?utm_campaign=homeAdUOA?Si,

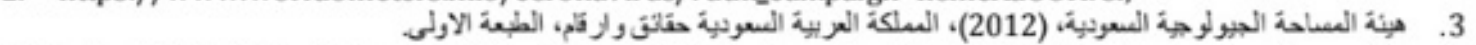

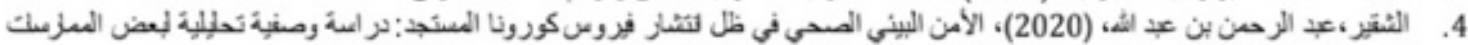

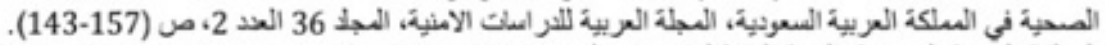

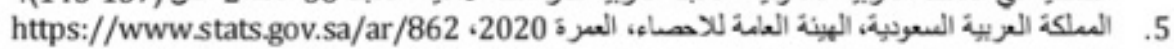

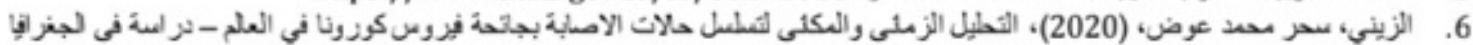

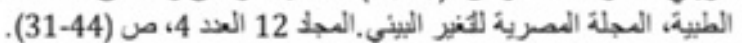

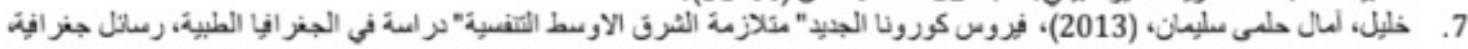

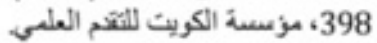

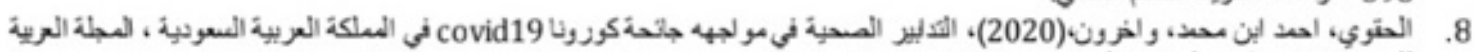

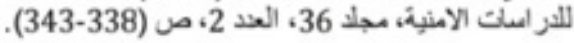

9. https://www.princeton.edu/news/2020/05/18/local-climate-unlikely-drive-early-covid-19-pandemic

10. Hariyono E., et al, (2021), Analysis of Temperature and Relative Humidity towards the Dispersion of CoVid19 in Indonesia, In Journal of Physics: Conference Series (Vol. 1747, No. 1, p. 012030). IOP Publishing https://iopscience.iop.org/article/10.1088/1742-6596/1747/1/012030

11. Mecenas P., et al, (2020), Effects of temperature and humidity on the spread of COVID-19: A systematic review, PLOS one, 15(9), e0238339 https://doi.org/10.1371/journal.pone.0238339

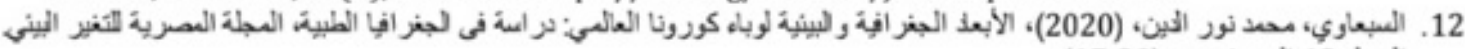

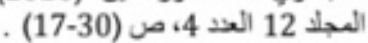

13. Kadi N. \& Khelfaoui M., (2020), population density a factor in the spread of COVID-19 in Algeria: ststistic study, Bulletin of the National Research Center, 44(1), 1-7 https://doi.org/10.1186/s42269-020-00393-x

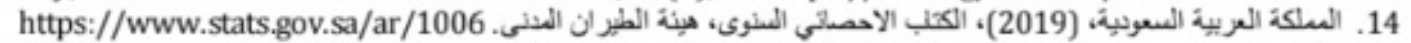

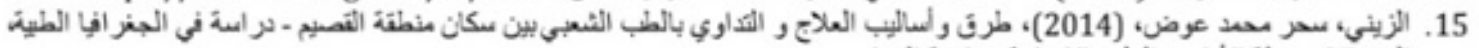

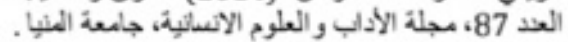

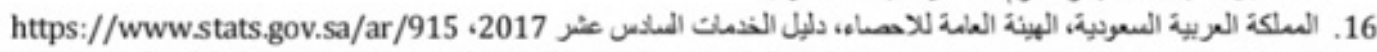

17. http://www.healthdata-org/news-release/lancet-latest-global-disease-estimates-reveal-perfect-stormrising-chronic-diseases-and

18. World Health Organization, (2020), Infection Prevention and Control Guidance for COVID-19, https://www.who.int/emergencies/diseases/novel-coronavirus-2019/technical-guidance/infectionprevention-and-control

19. World Health Organization, (2020), Coronavirus disease 2019 (COVID-19) Situation Report, 1196.https://www.who.int/emergencies/diseases/novel-coronavirus-2019/situation-reports/

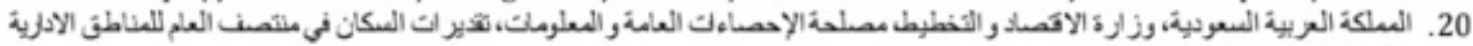

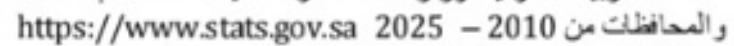

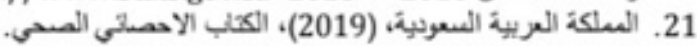

https://www.moh.gov.sa/Ministry/Statistics/book/Pages/default.aspx

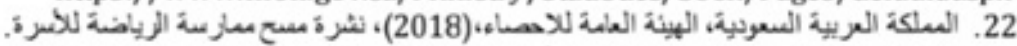

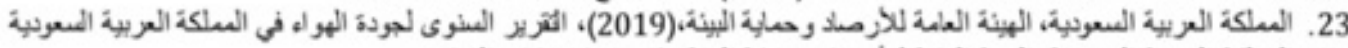

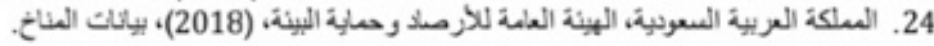

